\title{
Avaliação de terras em áreas de assentamento rural no município de Rio Preto da
}

\section{Eva, Amazonas: estudo de caso}

\author{
Land evaluation in settlement areas for agrarian reform in the municipality of Rio Preto da Eva,
} Amazonas: a case study

Evaluación de tierras en áreas de asentamiento para la reforma agraria en el municipio de Rio

Preto da Eva, Amazonas: un estudio de caso

Recebido: 29/07/2021 | Revisado: 02/08/2021 | Aceito: 13/08/2021 | Publicado: 16/08/2021

\author{
Vanessa Araújo Castelo Branco \\ ORCID: https://orcid.org/0000-0003-3637-3354 \\ Universidade Federal do Amazonas, Brasil \\ E-mail: v.araujo.cb@gmail.com \\ Marcileia Couteiro Lopes \\ ORCID: https://orcid.org/0000-0002-7953-5336 \\ Universidade Federal do Amazonas, Brasil \\ E-mail:mlopes@ufam.edu.br \\ Norma Cecilia Rodriguez Bustamante \\ ORCID: https://orcid.org/0000-0003-0589-785X \\ Universidade Federal do Amazonas, Brasil \\ E-mail: ncbustamante@gmail.com
}

\begin{abstract}
Resumo
Considerando que a valoração de terrenos rurais, ainda é uma temática pouco estudada e explorada, principalmente no Estado do Amazonas, devido à escassez de literatura e de profissionais especializados, o presente trabalho teve como objetivo aplicar metodologias de valoração em terrenos rurais situados no Projeto de Assentamento Rural para reforma Agrária Iporá, ramal Manápolis, município de Rio Preto da Eva, Amazonas. Os esforços na realização desta pesquisa consistiram na busca de uma definição de parâmetros para a avaliação de imóveis em áreas rurais do Amazonas. A pesquisa foi permeada pelos conceitos da engenharia de avaliações e como estratégia de pesquisa de campo foi escolhido o estudo de caso baseando-se nas evidências quali-quantitativas observadas. O Método de análise selecionado foi o Comparativo Direto de Dados de Mercado, em que o valor do terreno ou de suas benfeitorias é obtido mediante comparação de dados de mercado relativos a outros terrenos com características similares, utilizando-se fatores específicos de acordo com a realidade da área ou da região, por tratamento técnico de seus atributos. No universo dos terrenos existentes no ramal Manápolis foi escolhido um terreno avaliando (principal) e nove amostras semelhantes ao elemento amostral avaliado. Todos os elementos amostrais foram homogeneizadas por meio de fatores para que o erro amostral fosse minimizado. Ao final desta pesquisa concluímos que fatores como a localização, regularidade do terreno, acesso facilitado, vias de escoamento em situação de praticabilidade, dentre outros, exercem influência na valoração de terrenos rurais em municípios do Amazonas.
\end{abstract}

Palavras-chave: Valoração; Imóveis Rurais; Mercado.

\begin{abstract}
Considering that the valuation of rural land is still a subject that has been little studied and explored, mainly in the State of Amazonas, due to the lack of literature and specialized professionals, this study aimed to apply valuation methodologies in rural land located in the Project of Rural Settlement for Agrarian Reform Iporá, Manápolis branch, municipality of Rio Preto da Eva, Amazonas. Efforts to carry out this research consisted in the search for a definition of parameters for the valuation of properties in rural areas of Amazonas. The research was permeated by the concepts of engineering evaluations and as a field research strategy the case study was chosen according to Yin (2015), based on the quali-quantitative evidence observed. The method of analysis selected was the Direct Comparison of Market Data, in which the value of the land or its improvements is obtained by comparing market data relating to other land with similar characteristics, using specific factors according to reality area or region, by technical treatment of its attributes. In the universe of existing lands in the Manápolis branch, one land was chosen evaluating (main) and nine (nine) samples similar to the evaluated sample element. All sample elements were homogenized using factors so that the sampling error was minimized. At the end of this research, we concluded that factors such as location, land regularity, easy access, drainage routes in a practical situation, among others, influence the valuation of rural land in Amazonas municipalities. Keywords: Stocking; Rural Real Estate; Market.
\end{abstract}




\begin{abstract}
Resumen
Considerando que la valoración del suelo rural es aún un tema poco estudiado y explorado, principalmente en el Estado de Amazonas, debido a la falta de literatura y profesionales especializados, este estudio tuvo como objetivo aplicar metodologías de valoración en suelo rural ubicado en el Proyecto. de Asentamiento Rural para la Reforma Agraria Iporá, Ramal Manápolis, municipio de Rio Preto da Eva, Amazonas. Los esfuerzos para llevar a cabo esta investigación consistieron en la búsqueda de una definición de parámetros para la valoración de propiedades en áreas rurales de Amazonas. La investigación estuvo permeada por los conceptos de evaluaciones de ingeniería y como estrategia de investigación de campo se eligió el estudio de caso de acuerdo con Yin (2015), con base en la evidencia cualicuantitativa observada. El método de análisis seleccionado fue el de Comparación Directa de Datos de Mercado, en el cual el valor del terreno o sus mejoras se obtiene comparando datos de mercado relacionados con otros terrenos de similares características, utilizando factores específicos según la realidad del área o región, por tratamiento técnico. de sus atributos. En el universo de terrenos existentes en el ramal Manápolis, se eligió un terreno evaluando (principal) y nueve (nueve) muestras similares al elemento muestral evaluado. Todos los elementos de la muestra se homogeneizaron utilizando factores para minimizar el error de muestreo. Al final de esta investigación, se concluye que factores como la ubicación, regularidad de la tierra, fácil acceso, vías de drenaje en situación práctica, entre otros, influyen en la valoración del suelo rural en los municipios de Amazonas.
\end{abstract}

Palabras clave: Medias; Bienes Raíces Rurales; Mercado.

\title{
1. Introdução
}

A terra é o bem de maior valor para quem sobrevive do que ela produz, seja para o autoconsumo ou para geração de renda, então como avaliar esse bem? Um "pedaço de terra" tem tantas finalidades que perpassam por áreas que vão desde as relacionadas com atividades econômicas, sociais, culturais e ambientais. Porém, geralmente quando se fala de um imóvel rural relaciona-se este basicamente às atividades agropastoris, tendo como principal função a geração de alimento, considerando em sua avaliação a capacidade produtiva e seu estado atual (Breder, 2013).

Em áreas de assentamento, a terra tem um sentido de propriedade específico. Os assentados e os lotes recebidos são vinculados ao INCRA até o momento que sejam lavradas as escrituras, com isso os lotes não podem ser vendidos, doados ou arrendados (INCRA, 2016), pois cada um desses terrenos é entregue a uma família sem condições econômicas para adquirir e manter um imóvel rural por outras vias e se comprometem em morar na parcela e explorá-la para seu sustento, utilizando exclusivamente a mão de obra familiar na produção de alimentos, pois cada lote em um assentamento é uma unidade da agricultura familiar.

A Instrução Normativa $\mathrm{N}^{\circ} 30$, de 24 de fevereiro de 2006, que dispõe sobre Procedimento administrativo para a transferência de domínio, em caráter provisório ou definitivo, de imóveis rurais em projetos de assentamento de reforma agrária em terras públicas de domínio do INCRA ou da União, resolve:

“(...) Art. 2. O imóvel será transferido ao beneficiário de projeto de Reforma Agrária em caráter provisório, mediante Contrato de Concessão de Uso - CCU (anexo I) e em caráter definitivo, mediante Título de Domínio - TD.

Nesse sentido, o proprietário só estará definitivamente apto para a posse do imóvel, após 23 anos, sem infringir nenhuma das cláusulas do CCU ou qualquer que seja o instrumento legal, e, por fim deverá estar com toda a documentação do imóvel completa. Ainda assim, mesmo que o terreno não esteja apto para comercialização é importante valorá-lo para desenvolver metodologias e técnicas de acordo com as especificidades de cada região, que sirvam como base para terrenos aptos e legalizados. O importante é que o modelo resultante possa expressar o mais próximo possível, o valor real, para os terrenos naquela região, considerando além da terra, as áreas vegetadas, as benfeitorias e tudo o que nela existe (Dantas, 2005).

Petersen e Danilevicz (2006), ressaltam que é de extrema importância o conhecimento de atributos valorativos, os quais influenciam a formação do valor de bens, pois o valor dos bens imóveis reside na sua capacidade de gerar renda, proporcionada por seus atributos ambientais, pela localização, condições de acesso, infraestrutura nas proximidades, aptidão dos solos, 
capacidade de gerenciamento, dentre outras inúmeras variáveis, individualizando-os em uma amostra única, com suas particularidades inerentes (Lima, 2011).

Considerando que se, por um lado, valoração/avaliação de imóveis rurais, ainda é um assunto pouco estudado e explorado, principalmente no estado do Amazonas, em razão da escassez de literatura e déficit de profissionais, por outro lado, revela-se como uma área de grandes perspectivas para o futuro e verdadeira chance aos profissionais engenheiros em ampliar seus conhecimentos, adquirir experiência, criar oportunidade de fonte de renda, frente à larga extensão territorial do Estado.

Nesse contexto, este estudo foi desenvolvido junto aos imóveis rurais do Assentamento Rural Iporá, localizado no município de Rio Preto da Eva, Estado do Amazonas. A economia do Assentamento gira em torno da produção de farinha de mandioca, macaxeira e frutas, além da piscicultura e do artesanato (França, 2003).

O Assentamento Iporá possui características próprias para estudos de avaliações/valoração de imóveis rurais, em função de sua localização e economia. Permitindo assim, desenvolver, analisar e principalmente, conhecer a aplicabilidade das técnicas e dos fundamentos das normas vigentes, primordiais na prática de avaliação de áreas rurais.

Com base nessa premissa, a presente pesquisa consistiu na aplicação das metodologias avaliatórias de um imóvel na área do assentamento, bem como, de suas normas, procedimentos, legislação e a utilização do método comparativo direto de dados de mercado, cujos fundamentos se encontram alicerçados na Engenharia de Avaliações.

\section{Metodologia}

\section{1 Área de estudo}

O Projeto de Assentamento (PA) Iporá, foi criado no dia 13 de maio de 1991 com 27.809,7472 hectares pelo Instituto Nacional de Colonização e Reforma Agrária (INCRA). Localizado entre os quilômetros 127 e 146 da margem direita da Rodovia AM-010 - Manaus/Itacoatiara, em parte dos municípios de Rio Preto da Eva e de Itacoatiara, pertencentes à microrregião 010 Médio Amazonas. Distante aproximadamente $50 \mathrm{~km}$ da sede do município do Rio Preto da Eva, $80 \mathrm{~km}$ da sede do município de Itacoatiara e de 127 km da sede do município de Manaus, capital do estado do Amazonas (INCRA, 2016; Figura 1).

A produção agrícola é variada, com destaque para as culturas da macaxeira, laranja, cupuaçu, banana e a criação de frangos, patos e peixes: como o matrinxã e tambaqui. A comercialização ocorre junto a CONAB (Companhia Nacional de Abastecimento) e ao Governo do Estado (INCRA, 2007). 
Figura 1. Representação cartográfica da área de estudo no município de Rio Preto da Eva - AM.

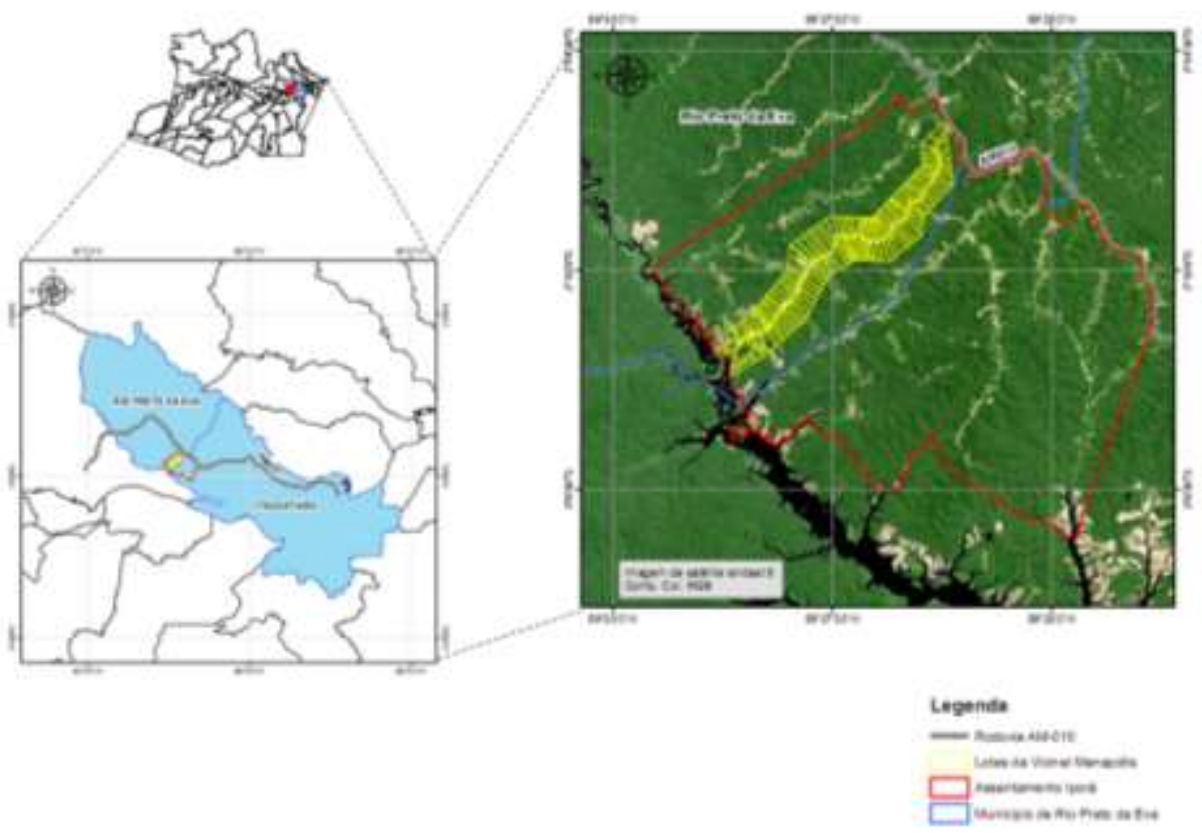

Fonte: Elaborado por Lemos, J. (2018).

O PA Iporá possui um sistema viário que dá acesso aos 422 lotes dessa área, sendo constituído pelas vias fluviais do Rio Preto da Eva, Igarapé Santa Cruz e Igarapé Grande, totalizando aproximadamente 24 quilômetros em linha reta e pelas vias terrestres da Rodovia AM - 010 - Manaus/Itacoatiara. O acesso ao PA Iporá e aos lotes dos assentados ocorre pelo ramal principal, denominado Manápolis, um dos ramais mais antigos no assentamento, com 17 km aproximadamente e 137 lotes, sendo este ramal o escolhido para a realização deste estudo. A partir do Manápolis, existem diversos ramais que facilitam o acesso aos lotes mais distantes (INCRA, 2016). O ramal Manápolis não possui pavimentação, e é transitável sem maiores complicações no período de seca, seis meses ao longo do ano. No período de chuva veículos com tração são mais indicados para transitarem no local.

De uma forma geral, todos os assentados são agricultores familiares que cultivam basicamente para o consumo próprio e comercializam o excedente para geração de renda. A maioria dos lotes possuem as mesmas espécies frutíferas plantadas, como côco, banana, cupuaçu, castanha, rambutã, abacate, açaí, maracujá, pupunha, tucumã, limão, goiaba e caju. A preferência pelo plantio e cultivo dessas espécies frutíferas é observada em outros assentamentos rurais de acordo com Silva (2009) e representa uma característica cultural dos agricultores familiares que garante alimento às suas famílias o ano todo. Também existe o cultivo de hortaliças como o coentro, cebolinha e chicória. E a criação de aves (patos e galinhas), suínos e peixes, em algumas propriedades.

A maioria das propriedades tem construções em madeira ou alvenaria, financiadas pelo crédito de construção e reforma concedido pelo INCRA ou com recursos dos assentados. Existe energia elétrica suprindo a necessidade de todos os terrenos, porém não há distribuição de água encanada e nem tratamento de esgoto.

\subsection{Coleta e Análise dos Dados}

Para este estudo, a coleta de dados, foi organizada em duas vertentes, a primeira sendo a pesquisa bibliográfica extensa sobre os preceitos teóricos da temática relacionada com a avaliação de imóveis rurais. A segunda, sendo a pesquisa de campo exploratória/observatória e de mercado com base nos preceitos estabelecidos. No contexto geral, as etapas foram distribuídas em coletas de dados qualitativos e quantitativos. Os dados vieram de várias fontes, e cada fonte associada a uma série de dados. 
Dentre as fontes mais usuais utilizadas estão a pesquisa de mercado, documentação e registros provenientes de órgãos públicos e cartórios, entrevistas não estruturadas, observação direta, diário de campo e registros fotográficos (Albuquerque, Lucena \& Alencar, 2010; Yin, 2015).

Nesta pesquisa, uma amostra representativa de dados de mercado de imóveis com características semelhantes às do imóvel avaliando foi constituída, usando-se toda a evidência disponível segundo o que preceitua a NBR 14653-3 (2004). Esta etapa teve início com a caracterização e delimitação do mercado em análise, com o auxílio de teorias e conceitos existentes ou hipóteses advindas de experiências adquiridas pelo avaliador sobre a formação do valor.

Os dados das amostras utilizadas neste estudo foram identificados e coletados ao acaso, com visitas in loco e levantamento por intermédio de questionário não estruturado aplicado individualmente em cada propriedade, além do uso de material fotográfico para caracterização geral do imóvel, dentre outros.

Concomitante a coleta de dados em campo, foi realizada uma pesquisa documental nas dependências do INCRAManaus, em documentos relativos ao histórico de criação do assentamento, plantas baixas, memorial descritivo, imagens de satélite, distribuição dos lotes, quantidade, área de cada lote e condição de regularização por parte do proprietário, lote(s) registrado(s), situação dominial, matrícula(s) e/ou registro(s), localização, coordenadas geográficas dos pontos extremos e acesso ao imóvel.

Após a coleta verificou-se que a quantidade de amostras era adequada e viável para análise e aplicação pretendida, pois conforme Kuhn et al. (2009), o que se pretende com a coleta de dados em uma pesquisa de imóveis é a composição de uma amostra representativa de dados de mercado, que contenha amostras com características mais semelhantes possíveis em relação ao bem que está sendo avaliado, usando-se todas as evidências disponíveis.

\subsection{Processamento e Análise dos Resultados}

A metodologia escolhida para avaliação dos imóveis rurais foi o Método Comparativo Direto, onde o valor do imóvel avaliando foi obtido mediante comparação de dados de mercado relativos a outros imóveis de características similares, por tratamento técnico de seus atributos (Fiker, 2011). O Método Comparativo é o mais frequente na avaliação de propriedades rurais, pois atenta-se a uma homogeneização mais cuidadosa, visto que as produções e a qualidade de terra podem não ser rigorosamente semelhantes, ainda que na mesma região (Abunahman, 2006).

Segundo Souza (2016), o fato de não haver igualdade entre propriedades rurais e sim semelhanças, é o ponto de partida para a homogeneização dos valores, que decorre da escolha mais adequada dos mecanismos de tratamento de dados de mercado, portanto, se faz obrigatório para a aplicação do método que haja, um tratamento técnico por fatores e o tratamento cientifico (ou por inferência estatística).

Assim sendo, a partir da aplicação do método, as amostras foram homogeneizadas de forma a garantir a comparação direta dos dados coletados com o avaliando, eliminando discrepâncias entre os elementos amostrais. As etapas de aplicação foram: caracterização da propriedade avaliada; pesquisa de dados relativos à propriedade semelhantes à propriedade avaliada $\mathrm{e}$ cálculo do valor da propriedade.

\subsection{Tratamento Estatístico}

O Tratamento de estatístico escolhido para avaliação dos imóveis rurais adotada para esta pesquisa foi o Tratamento por Fatores, que segundo a NBR 14653-3 podem ser adotados fatores de homogeneização medidos no mercado, com o campo de arbítrio determinado pelo intervalo de confiabilidade de $80 \%$ (oitenta por cento). O software utilizado para o processamento foi o de Avaliação de Imóveis Urbanos e Rurais (Moreira, 2016), com licença privada, que utiliza o processo de homogeneização por fatores. 
Os fatores de homogeneização utilizados para este estudo foram:

a. Fator de Fonte (fator de oferta ou de euforia $-F_{f}$ ) para corrigir as informações que não se caracterizam por transações efetivamente realizadas, é praxe utilizar 10\% (dez por cento) de quebra nas ofertas, vez que a barganha é sempre praticada antes da concretização do negócio;

b. Fator de Topografia - $\left(\mathrm{K}_{4}\right)$, considerando como situação paradigma um terreno plano onde o $\mathrm{K}_{4}=1,0$ e os terrenos com caimento para o fundo e para frente variam de acordo com a declividade;

c. Fator de Superfície e Solo - $\left(\mathrm{K}_{5}\right)$, considerando como situação paradigma um terreno seco e firme onde o $\mathrm{K}_{5}$ = 1,0 ou superfícies variando de úmida até permanentemente alagadas;

d. Fator de Acessibilidade - $\left(\mathrm{K}_{6}\right)$, considerando como situação paradigma um terreno sem condução próxima até $1.000 \mathrm{~m}, \mathrm{~K}_{6}=1,0$;

e. Fator de Área - (Fa), considerando a diferença entre as áreas dos imóveis amostrados e o imóvel em avaliação de acordo com Abunahman (2006).

Após a homogeneização dos dados, efetuou-se a análise estatística por meio do cálculo da média e do desvio padrão das amostras, avaliando a posição central e a dispersão do conjunto amostral, sendo influenciadas por valores discrepantes (Barbetta, 2005). Após a aplicação das equações de média e desvio padrão, a pertinência das amostras foi avaliada pelo critério excludente de Chauvenet (Abunahman, 2006). Em seguida realizamos a exclusão das amostras com diversidade muito elevada e aplicamos a teoria estatística das pequenas amostras, onde $n<30$ ), com a distribuição "t" de Student, para " $n$ " amostras e "n-1" graus de liberdade, com confiança de 80\%, conforme a Norma Brasileira 502/89 para a determinação do valor final do imóvel avaliando.

\section{Resultados e discussão}

\subsection{Descrição do Imóvel Avaliando e das amostras}

\subsubsection{Imóvel 00 ou Avaliando}

Imóvel rural situado no quilômetro oito do ramal, com casa sede construída em madeira e alvenaria, destinado à agricultura e pecuária evidenciados pelos plantios de macaxeira, pimenta do reino, castanha, laranja, rambutã, tucumã e criação de galinhas para venda de ovos. O imóvel apresenta um aviário e um galpão de construção em madeira, energia elétrica, caixa d'água de 1000L, e delimitações com cerca de arame farpado com cinco fios. A situação de ocupação de acordo com o INCRA é regular e a situação jurídica é de não titulado. $\mathrm{O}$ valor venal hipotético relatado pelo proprietário de acordo com as benfeitorias existentes estaria em torno de $\mathrm{R} \$ 80.0000,00$ (Figura 2). 
Figura 2. Representação fotográfica do imóvel avaliando no município do Rio Preto da Eva, Amazonas. A. Casa Sede; B. Cultivo de Mandioca; C. Imagem geral da propriedade; D. Cultivo de Laranja.
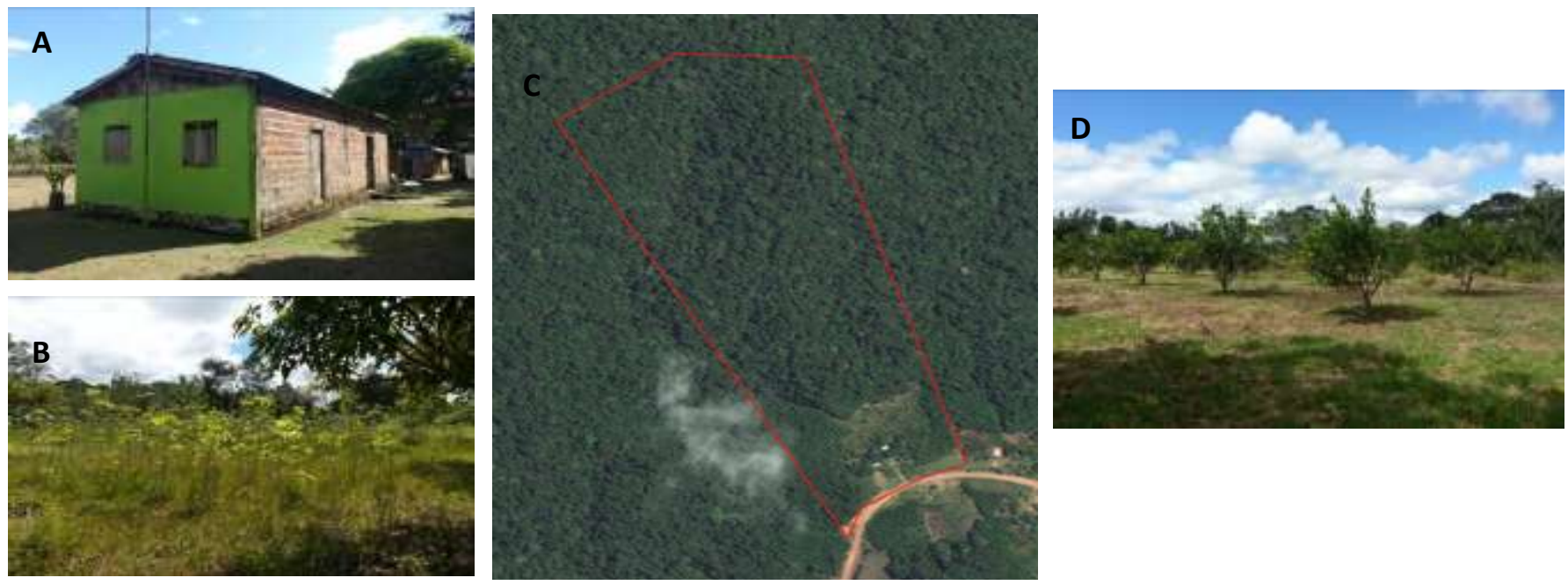

Fonte: Coletas de campo (Branco, V.A.C., 2016 - 2018); INCRA (2016).

\subsubsection{Imóveis amostrais}

No processo avaliatório realizou-se uma pesquisa de mercado para compor o conjunto de dados, onde as amostras selecionadas deveriam ter características semelhantes com a amostra avaliada. O levantamento de dados de mercado possibilitou a identificação de nove amostras com características similares ao imóvel avaliando, situadas no ramal Manápolis, Assentamento Iporá, Rio Preto da Eva - Amazonas. Os atributos das amostras estão descritos na Tabela 1 e seguem as informações de caracterização dos elementos amostrais, conforme os itens 7.4.1 e B.1.2 do Anexo B da NBR 14653-3:2004. 
Tabela 1. Dados dos elementos amostrais pesquisados dentre os imóveis rurais no município do Rio Preto da Eva, Amazonas.

\begin{tabular}{|c|c|c|c|c|}
\hline $\begin{array}{l}\text { Elementos } \\
\text { Amostrais }\end{array}$ & $\begin{array}{l}\text { Área } \\
\text { (ha) }\end{array}$ & $\begin{array}{c}\text { Localização } \\
\text { no Ramal }\end{array}$ & $\begin{array}{l}\text { Valor Venal } \\
\text { Hipotético }\end{array}$ & Atributos \\
\hline 01 & 20 & $\mathrm{Km} 11$ & $\mathrm{R} \$ 48.000,00$ & $\begin{array}{l}\text { Imóvel rural com casa sede de madeira, cerca de madeira, destinado à agricultura, com } \\
\text { plantios de côco, banana, macaxeira e árvores frutíferas como rambutã, cupuaçu, ingá, } \\
\text { dentre outros. }\end{array}$ \\
\hline 02 & 20 & $\mathrm{Km} 07$ & $\mathrm{R} \$ 150.000,00$ & $\begin{array}{l}\text { Imóvel rural com fundo para a reserva florestal do assentamento, com casa sede de madeira } \\
\text { onde existe um pequeno comércio de estivas, estruturas de tanque para a piscicultura, } \\
\text { chapéu de palha e aviário em madeira e cerca de arame farpado com } 5 \text { fios. Destinado à } \\
\text { agricultura, com produção de maracujá, banana, abobrinha, pimenta do reino, berinjela, } \\
\text { cheiro, chicória, cebolinha, dentre outros. Possui uma pequena criação de patos e galinhas, } \\
\text { apenas para consumo próprio. }\end{array}$ \\
\hline 03 & 25 & $\mathrm{Km} 08$ & $\mathrm{R} \$ 100.000,00$ & $\begin{array}{l}\text { Imóvel rural com edificação de duas casas sede em madeira, aviário em madeira, destinado } \\
\text { à agricultura. Existência das culturas de côco, banana e espécies como a castanha, } \\
\text { pupunha, jaca, andiroba, dentre outros. Possui uma pequena criação de patos e galinhas, } \\
\text { apenas para consumo próprio. }\end{array}$ \\
\hline 04 & 20 & $\mathrm{Km} 08$ & $\mathrm{R} \$ 500.000,00$ & $\begin{array}{l}\text { Imóvel rural com duas casas sede, sendo uma de alvenaria e outra de madeira, um galpão, } \\
\text { casa de farinha em madeira e } 02 \text { aviários, delimitado com portão e cerca de arame farpado. } \\
\text { Destinado à agricultura com plantios de banana, abobrinha, côco, cupuaçu, dentre outros. } \\
\text { Possui avicultura para venda de ovos e dos animais. }\end{array}$ \\
\hline 05 & 25 & $\mathrm{Km} \mathrm{3,5}$ & $\mathrm{R} \$ 150.000,00$ & $\begin{array}{l}\text { Imóvel rural com casa sede em madeira, galpão em madeira, sanitário em alvenaria, caixa } \\
\text { d'água de } 1000 \mathrm{~L} \text { e delimitações com portão e cerca de arame farpado com moirões em } \\
\text { madeira com } 6 \text { fios. Existência de plantio de árvores frutíferas como cupuaçu, rambutã, } \\
\text { tucumã, caju, côco, açaí, dentre outros. }\end{array}$ \\
\hline 06 & 25 & $\mathrm{Km} 11$ & $\mathrm{R} \$ 50.000,00$ & $\begin{array}{l}\text { Imóvel rural com construção de uma edificação mista em alvenaria e madeira, aviário em } \\
\text { alvenaria e madeira, energia elétrica, caixas d'água de } 1000 \mathrm{~L} \text { e } 5000 \mathrm{~L} \text {, e delimitações com } \\
\text { cerca de arame farpado de } 8 \text { fios. Destinado à agricultura com o plantio de cultivos de } \\
\text { côco, laranja e banana, além de castanha, tucumã, cupuaçu, dentre outros. Possui criação } \\
\text { de galinhas para venda. }\end{array}$ \\
\hline 07 & 25 & $\mathrm{Km} 11$ & $\mathrm{R} \$ 150.000,00$ & $\begin{array}{l}\text { Imóvel rural com duas edificações em alvenaria (casas sede), galpão em alvenaria e } \\
\text { madeira, caixa d'água de } 5000 \mathrm{~L} \text {, sem delimitações com cerca. Destinado à agricultura com } \\
\text { cultivos de banana, rambutã, goiaba, dentre outras espécies como castanha e tucumã. } \\
\text { Possui uma pequena atividade avícola de criação de patos e galinhas, apenas para consumo } \\
\text { próprio. }\end{array}$ \\
\hline 08 & 25 & $\mathrm{Km} 12$ & $\mathrm{R} \$ 250.000,00$ & $\begin{array}{l}\text { Imóvel rural com uma edificação em madeira, destinado à agricultura com plantios de } \\
\text { árvores frutíferas como cupuaçu, banana, pupunha, laranja em } 01 \text { ha e côco. Possui um } \\
\text { aviário e uma casa de farinha em construção, sem água encanada e não delimitado com } \\
\text { cerca. Existe também a criação de aves, como patos e galinhas, apenas para consumo } \\
\text { próprio. }\end{array}$ \\
\hline 09 & 25 & $\mathrm{Km} 12$ & $\mathrm{R} \$ 120.000,00$ & $\begin{array}{l}\text { Imóvel rural com uma edificação em alvenaria, destinado à agricultura com plantios de } \\
\text { côco, laranja, castanha, cupuaçu, tucumã, dentre outros. }\end{array}$ \\
\hline
\end{tabular}

Fonte: Levantamento de dados de mercado (2016 - 2018).

\subsection{Avaliação pelo Método Comparativo direto de Dados de Mercado}

No levantamento de dados, todas as amostras foram utilizadas como instrumento de estudo, com a aplicação do Método Comparativo Direto de Dados de Mercado, conforme a NBR 14.653-3. Neste estudo de caso, o valor de mercado determinado por este método será algo intrínseco ao bem e depende das variáveis de mercado consideradas, do ambiente e das técnicas para sua determinação (Dantas, 2012). Posteriormente à composição do banco de dados, todas as amostras foram homogeneizadas por meio de fatores para que o erro amostral fosse minimizado (Tabela 2). 
Tabela 2. Dados dos elementos amostrais homogeneizados pelo Método Comparativo Direto de Dados.

\begin{tabular}{|c|c|c|c|c|c|c|c|c|c|}
\hline $\mathbf{N}^{\circ}$ & Oferta (R\$) & $\begin{array}{c}\text { Área } \\
\text { (ha) }\end{array}$ & $\mathbf{V . U . ( R \$ / h a )}$ & $\mathbf{F}_{\mathbf{f}}$ & $\mathbf{K}_{\mathbf{4}}$ & $\mathbf{K}_{\mathbf{5}}$ & $\mathbf{K}_{\mathbf{6}}$ & $\mathbf{F}_{\mathbf{a}}$ & V.U.H (R\$/ha) \\
\hline $\mathbf{0 1}$ & $48.000,00$ & 20 & $2.400,00$ & 0,90 & 0,70 & 1,00 & 1,05 & 0,9457 & $1.501,3933$ \\
\hline $\mathbf{0 2}$ & $150.000,00$ & 20 & $7.500,00$ & 0,90 & 0,70 & 1,00 & 1,05 & 0,9457 & $4.691,8541$ \\
\hline $\mathbf{0 3}$ & $100.000,00$ & 25 & $4.000,00$ & 0,90 & 0,70 & 1,00 & 1,05 & 1,0000 & $2.646,0000$ \\
\hline $\mathbf{0 4}$ & $500.000,00$ & 20 & $25.000,00$ & 0,90 & 0,70 & 1,00 & 1,05 & 0,9457 & $15.639,5138$ \\
\hline $\mathbf{0 5}$ & $150.000,00$ & 25 & $6.000,00$ & 0,90 & 0,70 & 1,00 & 1,05 & 1,0000 & $3.969,0000$ \\
\hline $\mathbf{0 6}$ & $50.000,00$ & 25 & $2.000,00$ & 0,90 & 0,70 & 1,00 & 1,05 & 1,0000 & $1.323,0000$ \\
\hline $\mathbf{0 7}$ & $150.000,00$ & 25 & $6.000,00$ & 0,90 & 0,70 & 1,00 & 1,05 & 1,0000 & $3.969,0000$ \\
\hline $\mathbf{0 8}$ & $250.000,00$ & 25 & $10.000,00$ & 0,90 & 0,70 & 1,00 & 1,05 & 1,0000 & $6.615,0000$ \\
\hline $\mathbf{0 9}$ & $120.000,00$ & 25 & $4.800,00$ & 0,90 & 0,70 & 1,00 & 1,05 & 1,0000 & $3.175,2000$ \\
\hline
\end{tabular}

Legenda: V.U $\rightarrow$ Valor Unitário/V.U.H. $\rightarrow$ Valor Unitário Homogeneizado/ $\mathrm{F}_{\mathrm{f}} \rightarrow$ Fator de Fonte/K $\rightarrow$ Fator de Topografia/ $\mathrm{K}_{5} \rightarrow$ Fator de Superfície do Solo/ $\mathrm{K}_{6} \rightarrow$ Fator de Acessibilidade $/ \mathrm{F}_{\mathrm{a}} \rightarrow$ Fator de Área. Fonte: Autores.

As normas determinam que após o processo de homogeneização "devem ser utilizados critérios estatísticos consagrados de eliminação de dados discrepantes, para o saneamento da amostra" (Lima, 2011), conforme item B.1.3 do Anexo B da NBR 14653-3:2004. A utilização desses critérios permite guiar o desenvolvimento da avaliação, fornecendo um contexto que pode indicar mais claramente a relevância de casos e atributos, assim como ampliar a segurança das estimativas (Petersen \& Danilevicz, 2006). Desta forma, a partir dos valores homogeneizados encontrados observamos uma diferença significativa com relação aos elementos amostrais 1, 3, 4, 6 e 8, entre os preços de oferta (valores observados) e os valores estimados (valores calculados), essa diferença entre os valores se traduz no resíduo.

Figura 3. Representação gráfica comparativa entre os valores unitários dos elementos amostrais, valores unitários homogeneizados pela aplicação do método e resíduos.

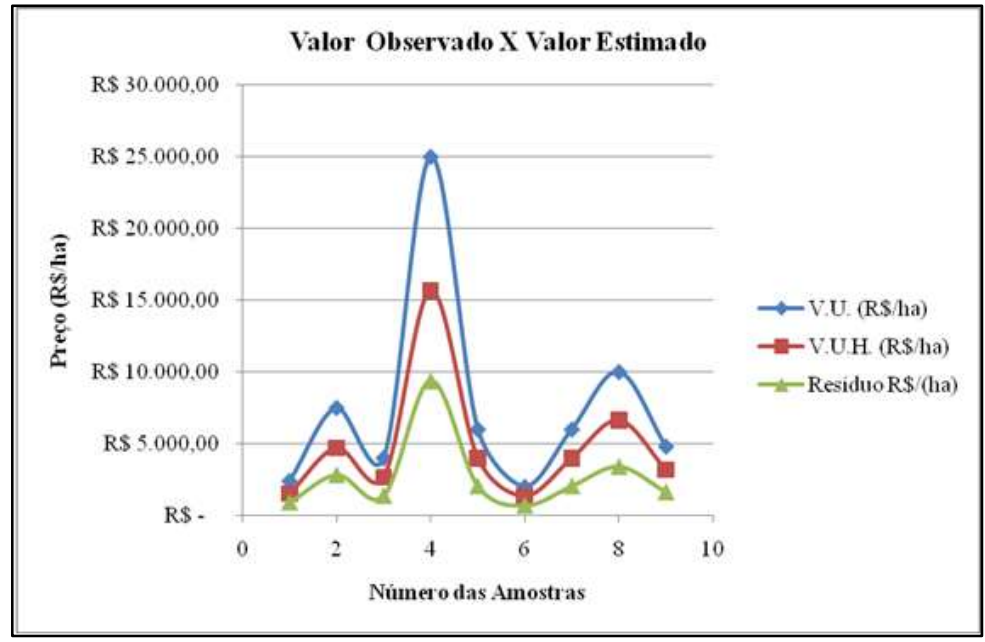

Fonte: Elaborado por Branco, V.A.C. (2016 - 2018).

De acordo com o Critério de Chauvenet, a amostra depois de homogeneizada será pertinente se o quociente entre sua média e o desvio padrão for inferior ao número crítico tabelado (Abunahman, 2006). Quando o valor é menor a amostra permanece como componente para a determinação dos valores. Quando o valor é superior o elemento amostral é eliminado para não comprometer a análise. 
Adotando-se que os valores críticos da distribuição em relação à média foram $0,8050<1,92$ e 2,4749 > 1,92, onde se aplicou Coeficiente de Chauvenet de 1,92, verifica-se que o $\mathrm{X}_{\text {inferior }}$ permanece e $\mathrm{X}_{\text {superior }}$ foi eliminado. Sendo assim, os valores críticos da distribuição na tabela 03 não satisfazem à condição, portanto, a amostra $\mathrm{n}^{\circ} 04$ contém elementos discrepantes, sendo rejeitada como elemento amostral.

Após a eliminação e exclusão da amostra ${ }^{\circ} 04$ foram realizados novamente todos os cálculos dos valores estatísticos para as 08 (oito) amostras restantes com relação à amostra principal a ser avaliada. Todas as amostras foram homogeneizadas novamente por meio de fatores para que o erro amostral fosse minimizado, seguindo-se com a determinação dos valores estatísticos.

Os valores homogeneizados dos imóveis variaram entre $\mathrm{R} \$ 1.323,00$ a $\mathrm{R} \$$ 6.615,00. O conjunto de fatores aplicados a cada elemento amostral foi considerado como homogeneizante quando após a aplicação dos respectivos ajustes, verificou-se que o conjunto de novos valores homogeneizados apresentava menor coeficiente de variação dos dados que o conjunto original. Nesses casos, segundo Oliveira (2006), os fatores devem refletir, em termos relativos, o comportamento do mercado, numa determinada abrangência espacial e temporal, a consideração da elasticidade de preços, da localização, dentre outros.

Tabela 3. Análise estatística dos elementos amostrais para n-1 graus de liberdade.

\begin{tabular}{|c|c|c|}
\hline Elemento Estatístico & Valor & Unidade \\
\hline Média Homogeneizada & $3.486,3059$ & $\mathrm{R} \$ / \mathrm{ha}$ \\
\hline Desvio-Padrão & $1.737,4337$ & $\mathrm{R} \$ / \mathrm{ha}$ \\
\hline Número de Amostras (n) & 8 & Amostras \\
\hline Grau de Liberdade (n-1) & 7 & Unidades \\
\hline Coeficiente de Chauvenet & 1,86 & \\
\hline Xinferior & 1,2451 & \\
\hline Xsuperior & 1,8008 & \\
\hline Xoeficiente de Student & 1,42 & \\
\hline Xmínimo & $2.553,8086$ & $\mathrm{R} \$ / \mathrm{ha}$ \\
\hline Xmáximo & $4.418,8032$ & $\mathrm{R} \$ / \mathrm{ha}$ \\
\hline Intervalo de Confiança & 932,4972 & $\mathrm{R} \$ / \mathrm{ha}$ \\
\hline Amplitude Mínima & $2.553,8086$ & $\mathrm{R} \$ / \mathrm{ha}$ \\
\hline Amplitude Máxima & $4.418,8032$ & $\mathrm{R} \$ / \mathrm{ha}$ \\
\hline Amtervalo Classe & 621,6649 & $\mathrm{R} \$ / \mathrm{ha}$ \\
\hline
\end{tabular}

Fonte: Dados processados e analisados por Branco, V.A.C. (2016 - 2018).

As medidas da tendência central são indicadores de como se distribuem os dados utilizados neste estudo, pois informam o valor (ou faixa de valores) da variável aleatória que ocorre com a maior frequência. Segundo Oliveira (2006), uma medida de tendência central é a mais importante de todas as mensurações numéricas descritivas na determinação de um imóvel rural, pois trata-se de um valor no centro ou no meio de um conjunto de dados.

Para o novo conjunto de dados, após a exclusão da amostra $\mathrm{n}^{\circ} 04$, observamos que ainda existiu uma diferença significativa com relação às amostras 1, 3, 6 e 8, sendo que se estes valores não houvessem sido homogeneizados, a diferença 
seria superior e o valor final do imóvel maior do que o calculado. Como estes dados foram homogeneizados em função dos fatores acima, presume-se que as demais características são absolutamente iguais ao avaliando.

A média e desvio padrão foram utilizadas para determinar os novos valores de $X_{\text {inferior }}=1,2451$ e $X_{\text {superior }}=1,8008$. Adotando-se os valores críticos da distribuição em relação à média foram 1,2451 <1,86 e 1,8008 > 1,86, onde se aplicou Coeficiente de Chauvenet de 1,86, verificou-se que o $X_{\text {inferior }}$ e o $X_{\text {superior }}$ refletem a pertinência das amostras, satisfazendo à condição de não conter elementos discrepantes entre as amostras de mercado utilizadas. A verificação da pertinência do rol das amostras pelo critério de Chauvenet (valor crítico $=1,86$ ), trouxe uma amplitude de 1.864,9946 e um valor de tomada de decisão de $\mathrm{R} \$ 3.439,80 /$ ha.

A valoração do imóvel considerando esses critérios quali-quantitativos de análise, assim como, seus atributos permitiu uma melhor estimativa de avaliação, gerando, portanto, para o imóvel, com área de 25 ha, avaliado estatisticamente a partir dos valores homogeneizados da série amostral coletada, ainda resguardados um intervalo de confiança de $80 \%$ (oitenta por cento), o valor final de $\mathrm{R} \$ 85.995,00$. Considerando o valor hipotético de oferta estabelecido pelo atual proprietário de $\mathrm{R} \$ 80.000,00$, observou-se que o valor calculado pelo método comparativo direto de dados de mercado representa quase o valor hipotético venal do imóvel avaliando.

\section{Conclusão}

Apesar da diversidade de ambientes e situações percebemos que é possível a aplicação ou testagem de metodologias avaliatórias em áreas rurais do Estado do Amazonas. Sendo necessário ainda, desenvolver, analisar e conhecer a aplicabilidade das técnicas existentes na literatura e dos fundamentos das normas vigentes na prática de avaliação de imóveis rurais.

A aplicação do método comparativo direto de dados de mercado em terrenos situados em assentamentos nos permitiu enxergar o leque de possibilidades, mas também as dificuldades de aplicação de qualquer metodologia avaliatória em áreas rurais do Amazonas. A insuficiência de informações públicas, o difícil acesso as áreas para levantamento de dados, a dificuldade em reunir amostras similares ao imóvel avaliando, escassez de bibliografia específica são fatores que tornam o processo avaliatório complexo. Ainda assim, a aplicabilidade do método comparativo direto de dados obteve a validação, em função dos atributos semelhantes encontrados no levantamento e coleta de dados, por meio do tratamento estatístico, por fatores, que direcionaram para a obtenção do valor final do imóvel avaliando. Porém, a especulação imobiliária, a regularidade do imóvel, a proximidade de centros urbanos, vias de escoamento, são fatores, dentre outros, que tornam tendencial a elevação do valor venal pelos proprietários dos imóveis rurais no Estado do Amazonas.

Portanto, é de suma relevância que esta área evolua mediante a realização de pesquisas que se fundamentem na legislação e normas direcionadas para sua aplicação, principalmente no Estado do Amazonas, frente à larga extensão territorial em função das diversas áreas rurais em desenvolvimento e em razão da escassez de literatura e déficit de profissionais.

\section{Referências}

ABNT - Associação Brasileira de Normas Técnicas. (2004). NBR14653-04: Avaliação de Bens. ABNT.

ABNT - Associação Brasileira de Normas Técnicas. (2001) NBR 14.653-1: Procedimentos gerais. ABNT

ABNT - Associação Brasileira de Normas Técnicas. (2004). NBR 14.653-3: Imóveis Rurais. ABNT.

ABNT - Associação Brasileira de Normas Técnicas, NB 502/89, Norma Brasileira para Avaliação de Imóveis Urbanos. dezembro de 1989.

Abunahman, S. A. (2006). Curso Básico de Engenharia Legal e de Avaliações. (3a ed.), Pini.

Albuquerque, U. P., Lucena, R. F. P., \& Alencar, N. (2010). Métodos e técnicas para coleta de dados etnobiológicos. NUPPEA, 41-64.

Barbetta, P. A. (2005). Estatística aplicada às Ciências Sociais. (5a ed.), Ed. da UFSC. 
Research, Society and Development, v. 10, n. 10, e477101018890, 2021

(CC BY 4.0) | ISSN 2525-3409 | DOI: http://dx.doi.org/10.33448/rsd-v10i10.18890

Breder, J. P. (2013). Avaliação de imóveis rurais. Monografia do Curso de Especialização em Construção Civil da Escola de Engenharia da Universidade Federal de Minas Gerais. Ênfase em Perícia e Avaliação. Escola de Engenharia.

Dantas, R. A. (2005). Engenharia de Avaliações - Uma Introdução À Metodologia Científica. (2a ed.), Pini.

Dantas, R. A. (2012). Engenharia de Avaliações: Uma introdução à metodologia científica. (3a ed.), rev. de acordo com a nova versão da NBR-14.653- 2:2011. Pini.

Fiker, J. Perícias e avaliações de Engenharia: Fundamentos Práticos. (2011). (2a ed.), Liv. E Ed. Universitária de Direito.

França, B.S. (2003). Energia, sociedade e recursos naturais em projetos de reforma agrária: Avaliação das condições de vida, possibilidades e dificuldades no assentamento Iporá (Rio Preto da Eva e Itacoatiara - AM). In: Encontro de Energia no Meio Rural.

INCRA - Instituto Nacional de Reforma Agrária. (2007). <http://www.incra.gov.br/>.

INCRA - Instituto Nacional de Reforma Agrária. (2016). <http://www.incra.gov.br/>.

INCRA - Instituto Nacional de Reforma Agrária (2006). Instrução Normativa no 30 de 24/02/2006. https://www.gov.br/incra/pt-br/centrais-deconteudos/legislacao/in_30_2006.pdf.

Kuhn, E. A., Pereira, L. P., \& Nerbas, P. de F. (2009). Avaliação de Imóveis e Perícias. IESDE Brasil S.A.

Lima, M. R. de C. (2011). Avaliação de propriedades rurais: manual básico: a engenharia de avaliações rurais aplicada às fazendas. (3a ed.), Leud.

Moreira, A. L. A. (2016). AVALURB: AM Projetos e Sistemas. www.amprosistemas.com.br.

Oliveira, A. M. B. D. (2006). Avaliações com Tratamento por Fatores. In: XXII Congreso Panamericano de Valuación e XIII Congresso Brasileiro de Engenharia de Avaliações e Perícias. Abril.

Petersen, F. B., \& Danilevicz, A. de M. (2006). Análise qualitativa e quantitativa de atributos valorativos de empreendimentos imobiliários em Porto Alegre Revista Gestão Industrial. 2, 63-74.

Silva, E. M. (2009). Diagnóstico no Município de São José do povo: Migrações, assentamentos, segurança alimentar e outros fatores de base para o desenvolvimento local. Campo Grande. Universidade Católica Dom Bosco. Centro de Pesquisa em Pós-graduação em Desenvolvimento Local - Mestrado Acadêmico.

Sousa, M. J. S. de. (2016). Avaliação de um imóvel rural: fazenda Bom Princípio - município de Guaiúba-CE (estudo de caso). Monografia (graduação) Universidade Federal do Ceará, Centro de Ciências Agrárias, Departamento de Engenharia Agrícola, Graduação em Agronomia, Fortaleza. 109 f.: il. color.

Yin, R. K. (2015). Estudo de caso: planejamento e métodos. (5a ed.), Bookman. 